\title{
Reference Ranges and Determinant Factors for Exhaled Nitric Oxide in a Healthy Korean Elderly Population
}

\author{
Eun-Jung Jo, ${ }^{1}$ Woo-Jung Song, ${ }^{2,3}$ Tae-Wan Kim, ${ }_{1}^{2,3}$ Heung-Woo Park, ${ }_{1}^{2,3}$ Yoon-Seok Chang, ${ }_{1}^{2,3}$ Tae-Bum Kim, ${ }_{1}$ \\ Sang-Heon Kim, ${ }_{1}^{6}$ Gyu-Young Hur, Jae-Hyung Lee, ${ }_{1}^{8}$ Ho-Joo Yoon, ${ }_{1}^{6}$ Hae-Sim Park ${ }_{1}^{9}$ Nam-Ho Cho, ${ }_{10}$ Hee-Bom Moon ${ }_{1}^{5}$ \\ Kyung-Up Min, ${ }^{2,3}$ Sang-Heon $\mathrm{Cho}^{2,3 *}$
}

\author{
'Department of Internal Medicine, Pusan National University School of Medicine, Busan, Korea \\ ${ }^{2}$ Department of Internal Medicine, Seoul National University College of Medicine, Seoul, Korea \\ ${ }^{3}$ Institute of Allergy and Clinical Immunology, Seoul National University Medical Research Center, Seoul, Korea \\ ${ }^{4}$ Department of Internal Medicine, Seoul National University Bundang Hospital, Seongnam, Korea \\ ${ }^{5}$ Department of Internal Medicine, Asan Medical Center, University of Ulsan College of Medicine, Seoul, Korea \\ ${ }^{6}$ Department of Internal Medicine, Hanyang University College of Medicine, Seoul, Korea \\ ${ }^{7}$ Department of Internal Medicine, Korea University College of Medicine, Seoul, Korea \\ ${ }^{8}$ Department of Internal Medicine, Eulji University College of Medicine, Seoul, Korea \\ ${ }^{9}$ Department of Internal Medicine, Ajou University College of Medicine, Suwon, Korea \\ ${ }^{10}$ Department of Preventive Medicine, Ajou University School of Medicine, Suwon, Korea
}

This is an Open Access article distributed under the terms of the Creative Commons Attribution Non-Commercial License (http://creativecommons.org/licenses/by-nc/3.0/) which permits unrestricted non-commercial use, distribution, and reproduction in any medium, provided the original work is properly cited.

Purpose: Exhaled nitric oxide (NO) is a useful non-invasive biomarker for asthma diagnosis; however, the literature suggests that exhaled NO levels may be affected by demographic factors. The present analysis investigated determinant factors that present exhaled NO reference levels for Korean elderly adults. Methods: For reference levels, we analyzed the baseline data of healthy adult participants in the Ansung cohort. The fraction of exhaled NO (FeNO) was measured by NIOX MINO ${ }^{\circledR}$. The characterization of the subjects was performed through structured questionnaires, spirometry, and methacholine challenge tests. To validate the diagnostic utility of the determined reference levels, asthma patients were recruited from medical institutions for FeNO measurement. Results: A total of 570 healthy subjects were analyzed (mean age, 59.9 12.3; male, 37.0\%) for reference levels. FeNO levels significantly correlated with weight, height, body mass index, atopy, or forced expiratory volume in 1 second \% predicted by simple linear regression analysis. Multiple linear regression analysis identified gender as an independent determinant for FeNO levels; subsequently, the reference values for FeNO were 18.2 $\pm 10.6 \mathrm{ppb}$ (5th to 95th percentile, 6.0 to $37.4 \mathrm{ppb}$ ) for males and 12.1 $\pm 6.9 \mathrm{ppb}$ (5th to 95th percentile, 2.5 to $27.0 \mathrm{ppb}$ ) for females. The diagnostic utility of FeNO reference levels was validated by receiver operating curve analysis (area under curve, 0.900 for males and 0.885 for females) for diagnosing asthma. The optimal cutoff values for the prediction of asthma were $30.5 \mathrm{ppb}$ for males and $20.5 \mathrm{ppb}$ for females. Conclusions: The current analysis presented reference ranges and the diagnostic utility of FeNO levels for asthma in Korean elderly adults.

Key Words: Adult; asthma; nitric oxide; reference values

\section{INTRODUCTION}

Asthma is characterized by variable airflow obstruction, bronchial hyperresponsiveness (BHR), and airway inflammation. ${ }^{1}$ In general, bronchial challenge tests (or induced sputum analysis) are applicable to assess BHR or underlying lung inflammation $^{2-4}$; however, the tests can be invasive as well as require specialized instruments and personnel. ${ }^{5}$

Nitric oxide (NO) is a gaseous molecule released by the human respiratory tract and increases under airway inflammatory con- ditions. ${ }^{6-11}$ Exhaled NO correlates well with eosinophilic airway inflammation and $\mathrm{BHR}^{12}$ and its measurement is safe. ${ }^{5,14,15}$ Current American Thoracic Society (ATS) guidelines recommend

Correspondence to: Sang-Heon Cho, MD, PhD, Department of Internal Medicine, Seoul National University College of Medicine, 101 Daehak-ro, Chongno-gu, Seoul 110-744, Korea.

Tel: +82-2-2072-2971; Fax: +82-2-742-2912; E-Mail: shcho@snu.ac.kr Received: April 9, 2013; Revised: July 12, 2013; Accepted: September 12, 2013

- There are no financial or other issues that might lead to conflict of interest. 
the use of the fraction of exhaled NO (FeNO) and induced sputum analyses to diagnose eosinophilic airway inflammation. ${ }^{7}$

Exhaled NO levels are influenced by various demographic factors $^{13,14}$; therefore, the reference range for clinical applications should be specifically determined for the population. Kim et $a l .{ }^{15}$ previously reported on FeNO reference ranges in Korea; however, the results were derived from relatively small-sized and younger adults ( $\mathrm{n}=166$; mean age, 32.7 years). In this context, the present study investigated FeNO reference ranges and determinants using the Ansung cohort dataset (a prospective community population cohort) in Korea.

\section{MATERIALS AND METHODS}

\section{Study population}

Study participants were recruited from the Ansung cohort. The design of this cohort and methods used have been previously described ${ }^{16}$ The Ansung cohort was established for the Korean Health and Genome Study in 2001 to investigate the frequency and determinants of chronic diseases in Korea. Participants included residents in a rural area $100 \mathrm{~km}$ south of Seoul. Sampling was based on mailing and door-to-door/telephone interview in 5 randomly selected governing regions.

From the 1,730 Ansung cohort participants, the present study initially analyzed 997 subjects who underwent NO measurement in 2011. The subjects were asked to answer structured questionnaires on medical history and allergic symptoms. Subjects underwent chest X-ray, spirometry, methacholine bronchial challenge tests, and allergen skin prick tests. The focus of the investigation was on reference ranges for healthy adults; therefore, we excluded individuals: (1) under 18 years old, (2) current smokers, (3) a previous diagnosis of allergic diseases (asthma, allergic rhinitis, atopic dermatitis, or chronic urticaria), (4) recent infections (within the past 3 weeks), (5) underlying lung diseases (bronchiectasis or chronic bronchitis) identified by questionnaire or chest X-ray, (6) current use of inhaled or systemic corticosteroids, (7) airway obstruction (defined by prebronchodilator forced expiratory volume in 1 second [FEV1] $\%$ predicted $<80 \%$ ), or (8) BHR (methacholine PC20 $<16 \mathrm{mg}$ / $\mathrm{mL}$ ). Study procedures were in accordance with institutional guidelines and approved by the institutional review board of Seoul National University Hospital. Informed consent was obtained from each participant.

\section{Fraction of exhaled NO measurement}

FeNO was measured using an online nitric oxide monitor (NIOX MINO, Aerocrine, Sweden) according to 2005 ATS/ERS guidelines. ${ }^{13}$ The subjects were asked about current medication or food intake that could interfere with the FeNO measurement results. In addition, they were instructed to avoid smoking, exercise, and ingestion of food, water or, caffeine at least 1 hour before testing.
The subjects exhaled fully while seated. The patient then inhaled over 2 to 3 seconds to total lung capacity through a NIOX filter and exhaled with an upper airway pressure of 5 to $20 \mathrm{~cm}$ $\mathrm{H}_{2} \mathrm{O}$. FeNO measurements were taken from a stable plateau of the exhaled NO concentration of at least 3 seconds during exhalation. The lowest detection limit of NIOX MINO was 5 parts per billion (ppb), and values less than $5 \mathrm{ppb}$ were considered $2.5 \mathrm{ppb}$. The average levels of at least 2 acceptable measurements were used.

\section{Spirometry and methacholine challenge test}

Pulmonary function was measured using a spirometry after FeNO measurement. The predicted values of FEV1 were calculated on the basis of the Morris method. ${ }^{17}$ Methacholine challenge tests were performed using a 5 -breath protocol with a dosimeter. ${ }^{18}$ Methacholine dilutions of $1,4,8$, and $16 \mathrm{mg} / \mathrm{mL}$ were used. Spirometry was performed 30 seconds and 90 seconds after each inhalation. The test was finished when FEV1 decreased by more than $20 \%$ from the baseline. A provocation concentration that caused a $20 \%$ decrease of FEV1 was defined as the provocation concentration dose for methacholine (PC20). BHR was defined as PC20 $<16 \mathrm{mg} / \mathrm{mL}$.

\section{Skin prick test}

An allergen skin test was performed using 12 common inhalant allergens in Korea: Dermatophagoides pteronyssinus, Dermatophagoides farinae, Alternaria tenuis, Aspergillus fumigatus, cockroach, cat, dog, early blossoming tree pollen mix (alder, hazel, poplar, elm, and willow tree), late blossoming tree pollen mix (birch, beech, oak, and plane tree), grass pollen mix (grass, barley, oat, rye, and wheat), ragweed, and mugwort. A $0.9 \%$ sodium chloride solution and a $1 \mathrm{mg} / \mathrm{mL}$ histamine solution were used as negative and positive controls, respectively. The test was considered positive when an allergen wheal to histamine wheal ratio was 1 or greater. Atopy was defined as positive skin test responses to any of 12 allergens.

\section{Recruitment of asthma patients}

To validate the diagnostic utility of FeNO reference levels, asthma patients were recruited from medical institutions (Seoul National University Hospital, Seoul National University Bundang Hospital, Asan Medical Center, Hanyang University Hospital, Korea University Hospital, Eulji University Hospital, and Ajou University Hospital). Asthma was diagnosed by typical asthma symptoms and positive BHR or a positive bronchodilator response (increase in FEV1 of $>12 \%$ predicted and $200 \mathrm{~mL}$ after inhalation of a short-acting $\beta_{2}$ agonist). Enrolled asthma patients were not currently receiving asthma medications, such as corticosteroids or antileukotrienes.

\section{Statistical analysis}

Statistical analysis was performed using the SPSS software (ver. 
19.0 for Window; SPSS, Inc., an IBM Company, Chicago, IL, USA). Data were presented as a number and percentage for categorical variables and mean \pm SD for continuous variables. Comparisons between variables were performed by Pearson's chisquare test for categorical variables and by Student's $t$-test for continuous variables. FeNO levels were not normally distributed; therefore, FeNO levels were log-transformed before analysis. Simple linear regression analysis determined the association of log-transformed FeNO (a dependent variable) with age, gender, weight, height, body mass index (BMI), atopy, and FEV1\% predicted. Potentially relevant factors (with $P<0.2$ in simple linear regression analysis) were included in multiple linear regression analysis. The reference values of FeNO are presented as mean \pm SD, median and interquartile range (IQR), and $90 \%$ confidence interval (CI, 5th to 95th percentile). Receiver-operator characteristic (ROC) analysis validated the diagnostic utility of FeNO from the combined group of healthy population and asthma patients. A $P$ value less than 0.05 was considered statistically significant.

\section{RESULTS}

\section{Baseline characteristics}

We included 570 subjects (mean age, 59.9 \pm 12.3 ; male, $37.0 \%$ )

Table 1. Clinical characteristics of study populations

\begin{tabular}{lcccr}
\hline Variables & $\begin{array}{c}\text { Total } \\
(\mathrm{n}=570)\end{array}$ & $\begin{array}{c}\text { Male } \\
(\mathrm{n}=211)\end{array}$ & $\begin{array}{c}\text { Female } \\
(\mathrm{n}=359)\end{array}$ & Pvalue \\
\hline Age (year) & $59.9 \pm 12.3$ & $56.5 \pm 12.3$ & $60.1 \pm 12.4$ & 0.623 \\
Weight (kg) & $62.0 \pm 10.5$ & $67.8 \pm 10.0$ & $58.6 \pm 9.3$ & $<0.001$ \\
Height $(\mathrm{cm})$ & $158.3 \pm 8.9$ & $166.4 \pm 6.7$ & $153.4 \pm 6.1$ & $<0.001$ \\
BMl $\left(\mathrm{kg} / \mathrm{m}^{2}\right)$ & $24.7 \pm 3.3$ & $24.4 \pm 3.0$ & $24.8 \pm 3.4$ & 0.141 \\
Smoking history & & & & \\
$\quad$ Non-smoker, $\mathrm{n}(\%)$ & $488(78.6)$ & $91(43.1)$ & $357(99.4)$ & $<0.001$ \\
$\quad$ Ex-smoker, $\mathrm{n}(\%)$ & $122(21.4)$ & $120(56.9)$ & $2(0.6)$ & $<0.001$ \\
Atopy, $\mathrm{n}(\%)$ & $133(23.3)$ & $72(34.1)$ & $61(17.0)$ & $<0.001$ \\
FEV1 $(\%$ predicted) & $102.3 \pm 14.9$ & $98.9 \pm 12.5$ & $104.3 \pm 15.8$ & $<0.001$ \\
\hline
\end{tabular}

$\mathrm{BMI}$, body mass index; FEV1, forced expiratory volume in 1 second.

Table 2. Association of log-transformed FeNO and independent variables by simple linear regression analysis

\begin{tabular}{lccr}
\hline Variable & Coefficient & Standard error & $P$ value \\
\hline Gender & 0.483 & 0.069 & $<0.001$ \\
Weight & 0.019 & 0.003 & $<0.001$ \\
Height & 0.023 & 0.004 & $<0.001$ \\
BMl & 0.026 & 0.011 & 0.014 \\
Atopy & 0.124 & 0.082 & 0.130 \\
FEV1 (\% predicted) & -0.007 & 0.002 & 0.004 \\
\hline
\end{tabular}

FeNO, fraction of exhaled nitric oxide; others as Table 1. after excluding $(n=427)$ subjects according to predetermined criteria (under 18 years old, $n=12$; current smoker, $n=169$; asthma, $n=20$; allergic rhinitis, $n=96$; atopic dermatitis, $n=16$; chronic urticaria, $n=2$; underlying lung diseases, $n=3$; current use of corticosteroids, $n=4$; airway obstruction, $n=127$; and $B H R, n=$ 13). Table 1 describes the baseline characteristics of the study subjects. Of the subjects, $133(23.3 \%)$ had atopy, which was more frequent in males than females $(P<0.001)$. Height and weight were greater in males, and FEV1 predicted values were higher in females; however, BMI did not differ.

\section{Determinant factors and reference ranges}

A simple linear regression analysis was performed to assess the association with age, gender, atopy, FEV1 predicted value, and anthropometric values (Table 2). Potentially relevant factors for FeNO $(P<0.2)$ were gender, weight, height, BMI, atopy, and FEV1 predicted value; however, age was not a meaningful determinant. In multiple linear regression analysis with adjustment for relevant factors ( $P<0.2$ in univariate tests), gender and weight were found to have significant associations with FeNO levels (Table 3 ). The intercept value was 1.546, and log-transformed FeNO increased by 0.376 in males compared to females when weight was assumed to be constant $(P<0.001)$. The statistical significance for weight was not correlated to FeNO levels in individual gender groups and suggested a confounding effect with gender (data not shown); therefore, reference values and basic statistics were derived with gender as the determinant factor for FeNO levels (Table 4). FeNO reference ranges were $18.2 \pm 10.6 \mathrm{ppb}$ in males and $12.1 \pm 6.9 \mathrm{ppb}$ in females. The $90 \%$ confidence interval (5th to 95th percentile) was 6.0 to $37.4 \mathrm{ppb}$ in males and 2.5 to 27.0 in females.

Table 3. Association between log-transformed FeNO and independent variables by multiple linear regression analysis

\begin{tabular}{lccr}
\hline Variable & Coefficient & Standard error & $P$ value \\
\hline Intercept & 1.546 & 0.207 & $<0.001$ \\
Gender & 0.376 & 0.075 & $<0.001$ \\
Weight & 0.012 & 0.003 & 0.001 \\
\hline
\end{tabular}

FeNO, fraction of exhaled nitric oxide.

Table 4. Reference values and basic statistics of FeNO levels

\begin{tabular}{lllc}
\hline & \multicolumn{3}{c}{ FeNO levels (ppb) } \\
\cline { 2 - 4 } & Mean \pm SD & \multicolumn{1}{c}{ Median (IOR) } & $90 \% \mathrm{Cl}^{*}$ \\
\hline Total $(\mathrm{n}=570)$ & $14.4 \pm 9.0$ & $13.0(8.0$ to 19.0$)$ & 2.5 to 31.0 \\
Male $(\mathrm{n}=211)$ & $18.2 \pm 10.6$ & $16.0(11.0$ to 25.0$)$ & 6.0 to 37.4 \\
Female $(\mathrm{n}=359)$ & $12.1 \pm 6.9$ & $11.0(7.0$ to 15.0$)$ & 2.5 to 27.0 \\
\hline
\end{tabular}

*Fitth to 95th percentile.

FeNO, fraction of exhaled nitric oxide; SD, standard deviation; IQR, interquartile range; $\mathrm{Cl}$, confidence interval. 

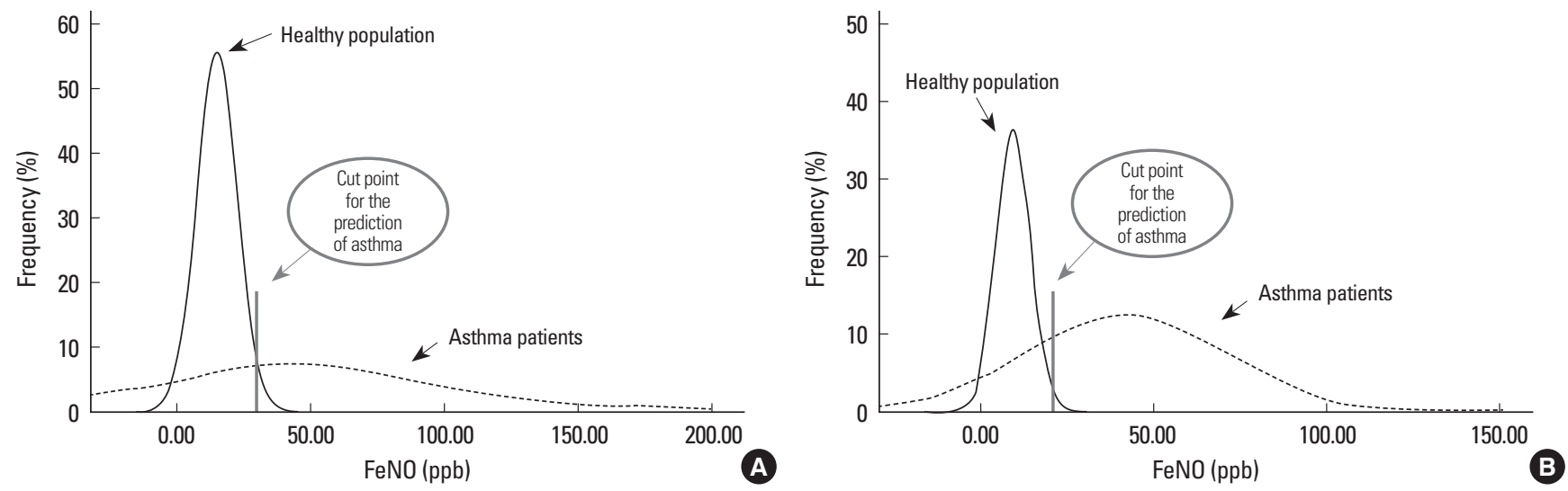

Fig. 1. The distribution of the fraction of exhaled nitric oxide (FeNO) in asthma patients and healthy population. (A) The distribution of FeNO for males. (B) The distribution of FeNO for females.
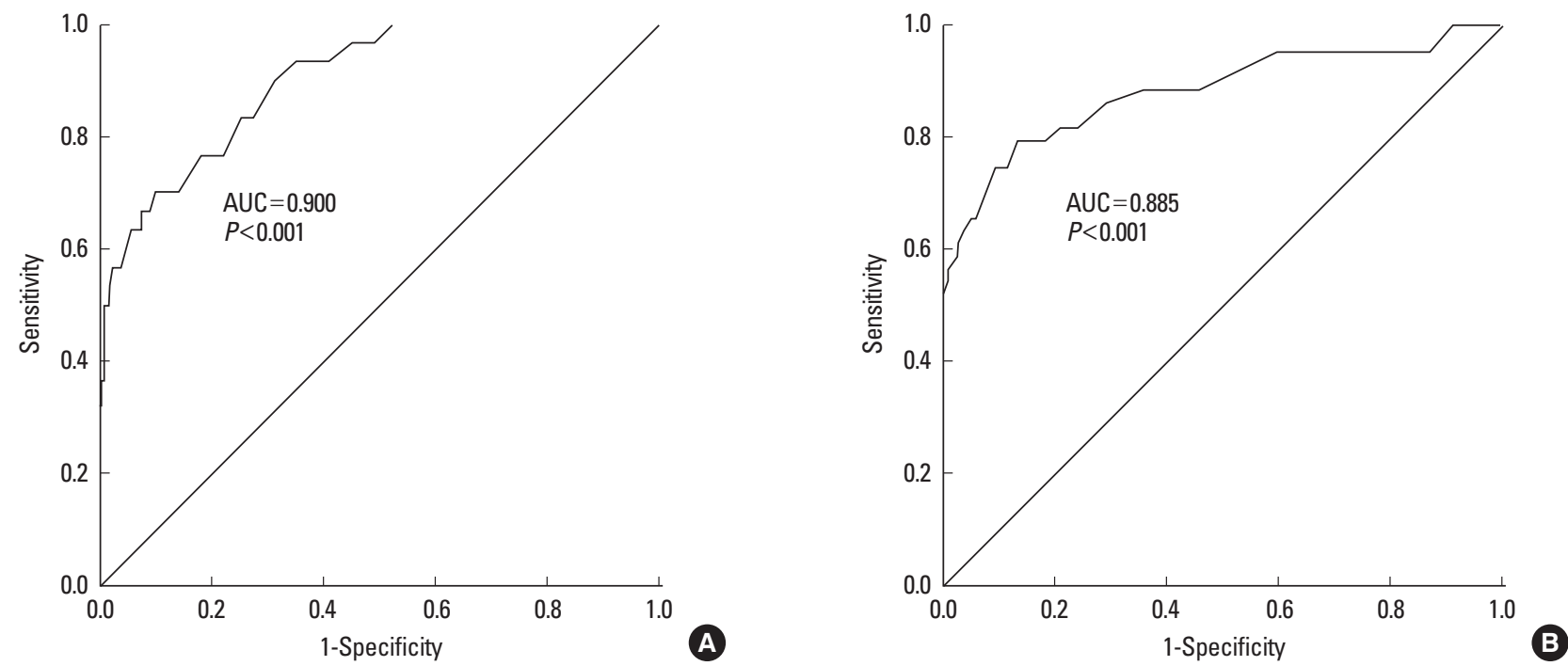

Fig. 2. Receiver-operator characteristic (ROC) analysis of the fraction of exhaled nitric oxide (FeNO). (A) ROC curve of FeNO for males ( $n=241$ ). (B) ROC curve of FeNO for females $(n=403)$.

\section{Utility of FeNO for the diagnosis of asthma}

We compared the distribution of FeNO levels in asthma patients and healthy population to validate the utility of FeNO (Fig. 1); subsequently, the ROC curves were constructed from the combined group of 570 healthy population and 74 asthma patients (mean age, $54.4 \pm 16.8$; male, $40.5 \%$; Table 5 ). The area under the ROC curve was 0.900 in males and 0.885 in females (Fig. 2). The sensitivity and specificity of FeNo measurement was $60 \%$ and $95.3 \%$ respectively in males $65.9 \%$ and $95.3 \%$ in females when the cutoff value of FeNO for the prediction of asthma was provided from the upper limit of $90 \%$ CI (37.4 ppb for males and $27.0 \mathrm{ppb}$ for females) (Table 6). The cutoff value from the best combination of sensitivity and specificity was $30.5 \mathrm{ppb}$ in males and $20.5 \mathrm{ppb}$ in females; this indicated a sensitivity of $70.0 \%$ and a specificity of $90.0 \%$ in males, a sensitivity of $79.5 \%$ and a specificity of $86.9 \%$ in females (Table 6).

\section{DISCUSSION}

The current analysis presented the FeNO reference range levels for healthy Korean elderly populations. We presented the gender-specific reference values of FeNO because gender was identified as a determinant factor; additionally, reference levels showed a good diagnostic utility for asthma diagnosis.

Our findings on gender association are consistent with those of previous reports ${ }^{15,19-22}$; however, mechanisms for the associations are unclear. A few hypotheses have been suggested in the literature. The first explanation is the effect of flow-induced dilution. ${ }^{23-25}$ The flow in small airways should be higher for the constant flow rate at the mouth level. FeNO would be lower in females with relatively smaller airways compared to males because exhaled NO is lower in a high flow. ${ }^{24}$ However, the limited reports on children indicate that FeNO levels correlate more significantly with age than gender ${ }^{26,27}$ Age-dependency in chil- 
Table 5. Comparison of baseline characteristics for healthy populations and asthma patients

\begin{tabular}{lccr}
\hline Variables & Healthy $(\mathrm{n}=570)$ & Asthma $(\mathrm{n}=74)$ & $P$ value \\
\hline Age (year) & $59.9 \pm 12.3$ & $54.4 \pm 16.8$ & 0.008 \\
Female, $\mathrm{n}(\%)$ & $359(63.0)$ & $44(59.5)$ & 0.556 \\
Weight $(\mathrm{kg})$ & $62.0 \pm 10.5$ & $63.1 \pm 9.8$ & 0.404 \\
Height $(\mathrm{cm})$ & $158.3 \pm 8.9$ & $161.0 \pm 8.3$ & 0.013 \\
BMl $\left(\mathrm{kg} / \mathrm{m}^{2}\right)$ & $24.7 \pm 3.3$ & $24.3 \pm 3.0$ & 0.334 \\
Smoking history & & & \\
Non-smoker, $\mathrm{n}(\%)$ & $488(78.6)$ & $56(75.7)$ & 0.567 \\
Ex-smoker, $\mathrm{n}(\%)$ & $122(21.4)$ & $18(24.3)$ & 0.567 \\
Atopy, $\mathrm{n}(\%)$ & $133(23.3)$ & $32(43.2)$ & $<0.001$ \\
FEV1 $(\%$ predicted) & $102.3 \pm 14.9$ & $84.8 \pm 26.0$ & $<0.001$ \\
FeNO levels & & & \\
Total (ppb) & $14.4 \pm 9.0$ & $52.9 \pm 38.2$ & $<0.001$ \\
Male (ppb) & $18.2 \pm 10.6$ & $64.5 \pm 46.3$ & $<0.001$ \\
Female (ppb) & $12.1 \pm 6.9$ & $44.9 \pm 29.6$ & $<0.001$ \\
\hline
\end{tabular}

$\mathrm{BMI}$, body mass index; FEV1, forced expiratory volume in 1 second.

dren, not gender-dependency, may be related to increased lung volume and airway surface area development. ${ }^{27}$ The difference in airway size may explain that exhalation flow rate in young children is relatively higher. The difference in lung volume and airway surface area may also account for an association between FeNO levels and height or weight, which are generally greater in males. Therefore, the difference in airway surface area may be considered as a crucial reason for a gender-related difference. ${ }^{20,25}$ An age-relationship does not seem evident in adult populations, ${ }^{15,19,28}$ and the present analysis did not indicate an association between age and FeNO levels.

Atopy was not an independent determinant for FeNO levels in our study population in contrast to the results of previous studies. ${ }^{21,22,29}$ A previous study with the Korean population conducted by Kim et al. ${ }^{15}$ in indicated that atopy (alongside gender) is a significant predictor of FeNO levels. The difference in the 2 Korean studies is assumed to have originated from the study population characteristics. Age distribution was considerably younger in the study conducted by Kim et al. (mean age, 33.7 years) than in our study (mean age, 59.9 years). In addition, the varying prevalence of atopy may have affected the statistical power ( $48 \%$ in the study conducted by Kim et al. vs $23.3 \%$ in our study). The negative findings on atopy association need to be confirmed by further studies with older adult populations; however, our findings potentially indicate significance in determining population-specific reference ranges.

Previous literature has suggested that FeNO levels are higher in Asians than in other ethnic groups ${ }^{24,26,27}$ and accounted for dietary differences, such as salted and nitrate-rich meals or genetic variations of the NO synthase gene. ${ }^{24,30}$ However, the present analysis did not find higher FeNO levels in Korean adults as compared to Western populations. ${ }^{5,21,28}$ Kharitonov et al. ${ }^{5}$ pre-
Table 6. Sensitivity, specificity, positive and negative predictive values, and diagnostic accuracy of FeNO for the diagnosis of asthma

\begin{tabular}{|c|c|c|c|c|c|}
\hline & $\begin{array}{c}\text { Sensitivity } \\
(\%)\end{array}$ & $\begin{array}{c}\text { Specificity } \\
(\%)\end{array}$ & $\begin{array}{c}\text { Positive } \\
\text { predictive } \\
\text { value }(\%)\end{array}$ & $\begin{array}{l}\text { Negative } \\
\text { predictive } \\
\text { value (\%) }\end{array}$ & $\begin{array}{c}\text { Predictive } \\
\text { accuracy } \\
(\%)\end{array}$ \\
\hline \multicolumn{6}{|c|}{ FeNO in males $(n=241)$} \\
\hline$>37.4 \mathrm{ppb}^{*}$ & 60 & 95.3 & 64.3 & 94.4 & 90.9 \\
\hline$>30.5 \mathrm{ppb}^{\dagger}$ & 70.0 & 90.0 & 50 & 95.5 & 87.6 \\
\hline \multicolumn{6}{|c|}{ FeNO in females $(n=403)$} \\
\hline$>27.0 \mathrm{ppb}^{*}$ & 65.9 & 95.3 & 63.0 & 95.8 & 92.1 \\
\hline$>20.5 \mathrm{ppb}^{\dagger}$ & 79.5 & 86.9 & 42.7 & 97.2 & 86.1 \\
\hline
\end{tabular}

*The cutoff value for the prediction of asthma was provided from the upper limit of $90 \%$ confidence interval (95th percentile) of FeNO levels derived from a healthy population; 'The cutoff value for the prediction of asthma was provided from the best combination of sensitivity and specificity for the diagnosis of asthma in the combined population.

FeNO, fraction of exhaled nitric oxide.

sented mean FeNO of $17.8 \pm 6.8 \mathrm{ppb}$ in a healthy adults study that demonstrated the reproducibility of FeNO for a healthy or asthma population in the UK (healthy adults $n=10$, age $=35.6 \pm$ 9.39, non-atopy). Travers et $a l_{.}{ }^{21}$ suggested a mean FeNO of 17.9 ppb in healthy New Zealander adults $(n=193$, mean age $=56.3 \pm$ 12.9, atopy rate $=23.8 \%$ ), and Olin et $_{\text {al. }}{ }^{28}$ showed a FeNO level of $16.6 \mathrm{ppb}$ in healthy Swedish adults ( $\mathrm{n}=1,131$; mean age, $50.3 \pm$ 13.81; atopy rate, 25.3\%). In Asia, Chng et al..$^{29}$ presented a median FeNO level of $38.4 \mathrm{ppb}$ for atopic subjects and $15.7 \mathrm{ppb}$ for non-atopic subjects in Singaporeans $(n=45$, mean age, 19.6; atopy rate, $61.8 \%$ ); however, their subjects were younger than ours. We speculate that the reason for our lower FeNO ranges (than other ethnic groups) may be due to differences in living environment. Our study populations were from rural areas, were less likely to be exposed to pollutants that could influence airway inflammation and were at lower risk for asthma. It is well-known that living in rural areas exerts a protective effect on asthma or atopy, ${ }^{31-33}$ as suggested by the "hygiene hypotheses.' The participants of previous studies were mostly recruited from urban areas. ${ }^{5,21,28,29}$

The relatively lower FeNO levels in our study could be related to inclusion/exclusion criteria. Previous studies did not exclude subjects with BHR; subsequently, their FeNO levels may have been affected by subjects with asymptomatic BHR. ${ }^{15,19,22}$

There are several limitations to our study. Our study population may not be representative of the entire Korean population. In particular, our participants were mostly older adult residents living in a rural area. In addition, the relatively low number of male subjects may have limited the statistical power and have resulted in the inclusion of ex-smokers. We did not match the age of the healthy population and asthma patients recruited to validate the utility of FeNO in the diagnosis of asthma because the number of asthmatic patients who underwent the FeNO measurement was small. However, age and a former history of 
smoking did not significantly correlate with FeNO levels. Despite the limitations, we expect our data to provide useful reference ranges for epidemiologic studies in elderly Korean adult populations. Recent literature suggests that asthma or allergic respiratory diseases are no longer childhood diseases ${ }^{34}$; subsequently, there is significant interest in epidemiologic surveys of asthma in an aged population. ${ }^{35-37}$ Our results are expected to be useful for older adult patients visiting medical institutions for asthma diagnosis as shown in ROC analysis.

In conclusion, we present FeNO reference ranges for healthy Korean elderly adults and a diagnostic utility for asthma.

\section{ACKNOWLEDGMENTS}

This study was supported by a Korea Healthcare technology R\&D project grant, Ministry of Health \& Welfare, Republic of Korea (A092076).

\section{REFERENCES}

1. International consensus report on diagnosis and treatment of asthma. National Heart, Lung, and Blood Institute, National Institutes of Health. Bethesda, Maryland 20892. Publication no. 92-3091, March 1992. Eur Respir J 1992;5:601-41.

2. Anderson SD, Brannan J, Spring J, Spalding N, Rodwell LT, Chan K, Gonda I, Walsh A, Clark AR. A new method for bronchial-provocation testing in asthmatic subjects using a dry powder of mannitol. Am J Respir Crit Care Med 1997;156:758-65.

3. Hunter CJ, Brightling CE, Woltmann G, Wardlaw AJ, Pavord ID. A comparison of the validity of different diagnostic tests in adults with asthma. Chest 2002;121:1051-7.

4. Maestrelli P, Saetta M, Di Stefano A, Calcagni PG, Turato G, Ruggieri MP, Roggeri A, Mapp CE, Fabbri LM. Comparison of leukocyte counts in sputum, bronchial biopsies, and bronchoalveolar lavage. Am J Respir Crit Care Med 1995;152:1926-31.

5. Kharitonov SA, Gonio F, Kelly C, Meah S, Barnes PJ. Reproducibility of exhaled nitric oxide measurements in healthy and asthmatic adults and children. Eur Respir J 2003;21:433-8.

6. Barnes PJ, Belvisi MG. Nitric oxide and lung disease. Thorax 1993; 48:1034-43.

7. Dweik RA, Boggs PB, Erzurum SC, Irvin CG, Leigh MW, Lundberg JO, Olin AC, Plummer AL, Taylor DR; American Thoracic Society Committee on Interpretation of Exhaled Nitric Oxide Levels (FENO) for Clinical Applications. An official ATS clinical practice guideline: interpretation of exhaled nitric oxide levels (FENO) for clinical applications. Am J Respir Crit Care Med 2011;184:602-15.

8. Fabbri LM, Romagnoli M, Corbetta L, Casoni G, Busljetic K, Turato G, Ligabue G, Ciaccia A, Saetta M, Papi A. Differences in airway inflammation in patients with fixed airflow obstruction due to asthma or chronic obstructive pulmonary disease. Am J Respir Crit Care Med 2003;167:418-24.

9. Kharitonov SA, Yates D, Barnes PJ. Increased nitric oxide in exhaled air of normal human subjects with upper respiratory tract infections. Eur Respir J 1995;8:295-7.

10. de Gouw HW, Grünberg K, Schot R, Kroes AC, Dick EC, Sterk PJ. Relationship between exhaled nitric oxide and airway hyperre- sponsiveness following experimental rhinovirus infection in asthmatic subjects. Eur Respir J 1998;11:126-32.

11. Barnes PJ, Liew FY. Nitric oxide and asthmatic inflammation. Immunol Today 1995;16:128-30.

12. Jatakanon A, Lim S, Kharitonov SA, Chung KF, Barnes PJ. Correlation between exhaled nitric oxide, sputum eosinophils, and methacholine responsiveness in patients with mild asthma. Thorax 1998; 53:91-5.

13. American Thoracic Society; European Respiratory Society. ATS/ERS recommendations for standardized procedures for the online and offline measurement of exhaled lower respiratory nitric oxide and nasal nitric oxide, 2005. Am J Respir Crit Care Med 2005;171:912-30.

14. Sandrini A, Taylor DR, Thomas PS, Yates DH. Fractional exhaled nitric oxide in asthma: an update. Respirology 2010;15:57-70.

15. Kim SH, Kim TH, Sohn JW, Yoon HJ, Shin DH, Park SS. Reference values and determinants of exhaled nitric oxide in healthy Korean adults. J Asthma 2010;47:563-7.

16. Shin C, Abbott RD, Lee H, Kim J, Kimm K. Prevalence and correlates of orthostatic hypotension in middle-aged men and women in Korea: the Korean Health and Genome Study. J Hum Hypertens 2004;18:717-23.

17. Morris JF. Spirometry in the evaluation of pulmonary function. West J Med 1976;125:110-8.

18. Crapo RO, Casaburi R, Coates AL, Enright PL, Hankinson JL, Irvin CG, MacIntyre NR, McKay RT, Wanger JS, Anderson SD, Cockcroft DW, Fish JE, Sterk PJ. Guidelines for methacholine and exercise challenge testing-1999. This official statement of the American Thoracic Society was adopted by the ATS Board of Directors, July 1999. Am J Respir Crit Care Med 2000;161:309-29.

19. Tsang KW, Ip SK, Leung R, Tipoe GL, Chan SL, Shum IH, Ip MS, Yan C, Fung PC, Chan-Yeung M, Lam W. Exhaled nitric oxide: the effects of age, gender and body size. Lung 2001;179:83-91.

20. Olivieri M, Talamini G, Corradi M, Perbellini L, Mutti A, Tantucci C, Malerba M. Reference values for exhaled nitric oxide (reveno) study. Respir Res 2006; 7:94.

21. Travers J, Marsh S, Aldington S, Williams M, Shirtcliffe P, Pritchard A, Weatherall M, Beasley R. Reference ranges for exhaled nitric oxide derived from a random community survey of adults. Am J Respir Crit Care Med 2007;176:238-42.

22. Ko FW, Leung TF, Wong GW, Chu JH, Sy HY, Hui DS. Determinants of, and reference equation for, exhaled nitric oxide in the Chinese population. Eur Respir J 2013;42:767-75.

23. Franklin PJ, Taplin R, Stick SM. A community study of exhaled nitric oxide in healthy children. Am J Respir Crit Care Med 1999;159: 69-73.

24. Wong GW, Liu EK, Leung TF, Yung E, Ko FW, Hui DS, Fok TF, Lai CK. High levels and gender difference of exhaled nitric oxide in Chinese schoolchildren. Clin Exp Allergy 2005;35:889-93.

25. Latzin P, Beck J, Griese M. Exhaled nitric oxide in healthy children: variability and a lack of correlation with atopy. Pediatr Allergy Immunol 2002;13:37-46.

26. Kovesi T, Kulka R, Dales R. Exhaled nitric oxide concentration is affected by age, height, and race in healthy 9- to 12-year-old children. Chest 2008;133:169-75.

27. Buchvald F, Baraldi E, Carraro S, Gaston B, De Jongste J, Pijnenburg MW, Silkoff PE, Bisgaard H. Measurements of exhaled nitric oxide in healthy subjects age 4 to 17 years. J Allergy Clin Immunol 2005; 115:1130-6.

28. Olin AC, Bake B, Torén K. Fraction of exhaled nitric oxide at $50 \mathrm{~mL} / \mathrm{s}$ : 
reference values for adult lifelong never-smokers. Chest 2007;131: 1852-6.

29. Chng SY, Van Bever HP, Lian D, Lee SX, Xu XN, Wang XS, Goh DY. Relationship between exhaled nitric oxide and atopy in Asian young adults. Respirology 2005;10:40-5.

30. Olin AC, Aldenbratt A, Ekman A, Ljungkvist G, Jungersten L, Alving $\mathrm{K}$, Torén K. Increased nitric oxide in exhaled air after intake of a nitrate-rich meal. Respir Med 2001;95:153-8.

31. Yemaneberhan H, Bekele Z, Venn A, Lewis S, Parry E, Britton J. Prevalence of wheeze and asthma and relation to atopy in urban and rural Ethiopia. Lancet 1997;350:85-90.

32. Ernst P, Cormier Y. Relative scarcity of asthma and atopy among rural adolescents raised on a farm. Am J Respir Crit Care Med 2000; 161:1563-6.

33. Lee SY, Kwon JW, Seo JH, Song YH, Kim BJ, Yu J, Park KS, Kim H, Kim EJ, Lee JS, Hong SJ. Prevalence of atopy and allergic diseases in Korean children: associations with a farming environment and rural lifestyle. Int Arch Allergy Immunol 2012;158:168-74.
34. Hanania NA, King MJ, Braman SS, Saltoun C, Wise RA, Enright P, Falsey AR, Mathur SK, Ramsdell JW, Rogers L, Stempel DA, Lima JJ, Fish JE, Wilson SR, Boyd C, Patel KV, Irvin CG, Yawn BP, Halm EA, Wasserman SI, Sands MF, Ershler WB, Ledford DK; Asthma in Elderly workshop participants. Asthma in the elderly: current understanding and future research needs--a report of a National Institute on Aging (NIA) workshop. J Allergy Clin Immunol 2011;128: S4-24.

35. Kim YK, Kim SH, Tak YJ, Jee YK, Lee BJ, Kim SH, Park HW, Jung JW, Bahn JW, Chang YS, Choi DC, Chang SI, Min KU, Kim YY, Cho SH. High prevalence of current asthma and active smoking effect among the elderly. Clin Exp Allergy 2002;32:1706-12.

36. King MJ, Hanania NA. Asthma in the elderly: current knowledge and future directions. Curr Opin Pulm Med 2010;16:55-9.

37. Enright PL, McClelland RL, Newman AB, Gottlieb DJ, Lebowitz MD. Underdiagnosis and undertreatment of asthma in the elderly. Cardiovascular Health Study Research Group. Chest 1999;116:603-13. 